\title{
Low concentration of putative anti-auxin and anti-fungal agent accelerates the PLB organogenesis of Dendrobium okinawense under green LED
}

\author{
Hasan Mehbub 1,*, Kazuhiko Shimasaki ${ }^{1,2}$ and Hasan Mehraj ${ }^{3, *}$ \\ 1 The United Graduate School of Agricultural Sciences, Ehime University, Ehime 790-8556, Japan; sujanha- \\ san@gmail.com (H. Mb.) \\ 2 Faculty of Agriculture, Kochi University, 200 Otsu, Monobe, Nankoku city, Kochi 783-8502, Japan; \\ shim@kochi-u.ac.jp (K. S.) \\ 3 Graduate School of Agricultural Science, Kobe University, Rokkodai, Nada-ku, Kobe 657-8501, Japan; \\ hmehraj34@stu.kobe-u.ac.jp or, hmehhraj02@yahoo.com (H. M.) \\ * Correspondence: hmehraj34@stu.kobe-u.ac.jp or, hmehhraj02@yahoo.com (H. M.); sujanhasan@gmail.com \\ (H. Mb.)
}

\begin{abstract}
Dendrobium okinawense is an endangered epiphytic orchid, and there has been no scientific report so far on its propagation. Protocorm is mass of cell, and protocorm-like bodies (PLBs) look alike protocorm produced by vegetative explants in vitro. Regeneration of PLBs is the most efficient technique for the orchids micro-propagation. We used different light emitting diodes (LEDs) for the efficient PLB organogenesis of D. okinawense. PLBs regenartion under green and red LED surpassed respectively $81.1 \%$ and $71.6 \%$ in numbers, and respectively $80.8 \%$ and $57.8 \%$ in fresh weight over white fluorescent light. We manipulated the culture media by different concentrations of PCIB and HMI. PLBs organogenesis promoted by low concentration, it increased respectively $35.9 \%$ and $19.3 \%$ over control by $0.01 \mathrm{mg} / \mathrm{L}$ PCIB and $0.01 \mathrm{ml} / \mathrm{L}$ HMI in numbers. Green LED and PCIB independently produced mostly similar numbers of new PLBs. Interestingly, culture media with 0.01 $\mathrm{mg} / \mathrm{L}$ of PCIB further increased $8.5 \%$ of the numbers of PLBs under green LED, whereas the culture media with $0.01 \mathrm{mg} / \mathrm{L}$ HMI reduced the number of PLBs under green LED. PLBs culture under green LED with very low concentrations of PCIB manipulated culture media can significantly increase their organogenesis of D. okinawense.
\end{abstract}

Keywords: Orchid, Protocorm-like bodies, p-Chlorophenoxyisobutyric acid, PCIB, 3-Hydroxy-5methyl isoxazole, HMI, light emitting diodes

\section{Introduction}

Orchids are important cut and pot flowering plants. In vitro micro-propagation is very common in orchid regenerations because of its complexity in vegetative and sexual propagations. Several in vitro techniques are followed for orchid micro-propagation, and propagation by PLB (protocorm-like-body) is one of them [1-3]. In vitro organogenesis of PLB was studied in different Dendrobium sp. [4-8]. D. okinawense is a Japanese native epiphytic orchid, and it is closely related to D. moniliforme [9]. It was firstly identified by Hatsushima and Ida (1970) [10] from Okinawa Island of Japan.

Plant tissue culture media can be manipulated by plant growth regulators such as auxin, cytokinin to influence in vitro growth and development. PCIB or, $p$-Chlorophenoxyisobutyric acid is known as a putative anti-auxin; and it is widely used to inhibit auxin action [11,12]. PCIB has antagonistic effect on IAA-induced inhibition, and it inhibits IAAinduced plant growth $[13,14]$. Polar auxin transport inhibitors can influence protocorm morphogenesis during its development [15]. An antifungal agrochemical, HMI (3-Hydroxy-5-methyl isoxazole) or Hymexazol (Tachigaren ${ }^{\mathrm{TM}}$ ) is a member of isoxazoles. It was firstly launched in 1960s to control seedling diseases, and improve plant vigor in rice [16]. It is also considered as plant growth-regulating agent [17]. The multiple abilities of HMI or, hymexazol [18] can promote the growth and development of different plant in vitro 
culture. Light is another key factor for in vitro propagation, and light emitting diodes (LEDs) provide much narrower wavelengths by offering plant specific light intensity and wavelength than the conventional fluorescent light [19-21]. Therefore, a specific and more precise spectral quality can be selected and adjusted to the requirements of specific plant [22]. LEDs have huge capacity for energy savings, and recently it has been used widely for commercial plant growth and plant research [23]. The absorption of the light spectrum is plant specific, and the absorption depends on some other factors as well. Diverse monochromatic light function differently in dissimilar species for in vitro plant growth and development [24,25]. Some studies were also reported about the effects of white, green, far red, yellow and orange LEDs in plant micropropagation [25-30]. LEDs are found more efficient over fluorescent light for orchid PLB organogenesis [6,7,31-40].

D. okinawense has been enlisted in endangered species list [41-43]. D. okinawense propagate in legal local markets in a tiny scale [44], which would not enough for their ex-situ conservation and genetic rescue. Availability of the micro-propagation technique can make this genetic conservation easier, and it will help to add one more orchid species in commercial flower market. We are reporting first time in vitro micro-propagation of $D$. okinawense by PLBs organogenesis. We conceptualized that supplementation of very low concentration of PCIB or, HMI in culture media and then culture under a specific LEDs can improve the PLBs organogenesis of D. okinawense.

\section{Results}

\subsection{Confirmation of the sucrose concentrations}

We previously observed that $20 \mathrm{~g} / \mathrm{L}$ sucrose is efficient for PLBs organogenesis in orchid plants [31-38]. However, in vitro PLB organogenesis can be plant specific, thereafter, we supplied $0,5,10,20,30$, and $40 \mathrm{~g} / \mathrm{L}$ of sucrose to the culture media, and five explants in each of $30 \mathrm{ml}$ culture media were cultured for 42 days to compare PLB organogenesis of D. okinawense. Culture chamber was adjusted to a 16-hour photoperiod (inflorescent light, $\left.50 \mu \mathrm{molem}^{-2} \mathrm{~S}^{-1}\right)$; temperature was set at $25 \pm 1^{0} \mathrm{C}$. We did not find any significant different between 10, 20 and $30 \mathrm{gL}^{-1}$ of sucrose (Supplementary Table S1). Then we used $20 \mathrm{~g} / \mathrm{L}$ sucrose as carbohydrate sources throughout the experiments.

\subsection{LEDs lights for PLB organogenesis of D. okinawense}

We evaluated the effect of four different LEDs for the PLB organogenesis of $D . o k i$ nawense. Red and green LED increased respectively $71.6 \%$ and $81.1 \%$ of the number of PLB, while respectively $57.8 \%$ and $80.8 \%$ of the average fresh weight over the white fluorescent light (Figure 1). We found the highest number of PLBs (8.93) per explants and maximum average fresh weight $(164.7 \mathrm{mg}$ ) from the PLBs cultured under green LED (Figure 1). Number of PLBs was statistically identical with the white fluorescent light, red LED and white LED (Figure 1a); while average fresh weight was statistically identical with green, red and white LED (Figure 1b). PLBs cultured under blue LED significantly reduced their organogenesis (Figure 1). The highest 0.93 shoot per explant was newly generated from the PLBs cultured under red LED, while green and white LED produced 0.67 shoot per explant (Table 1A). 


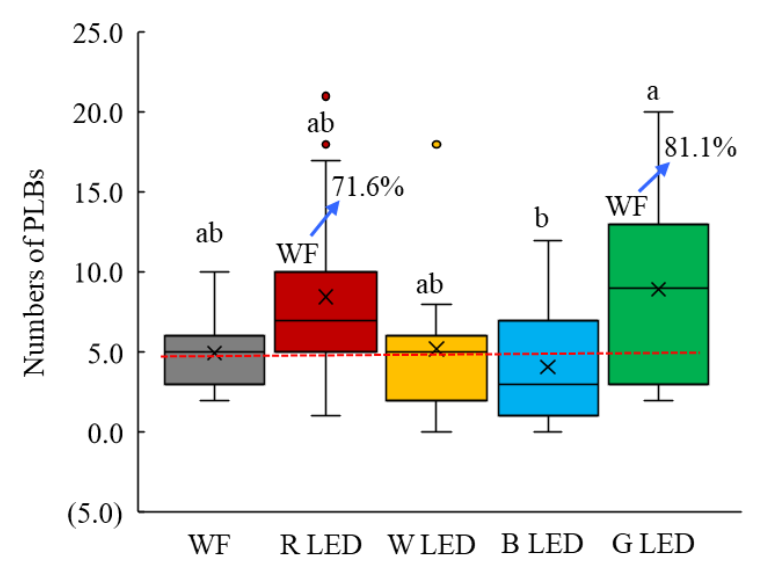

(a)

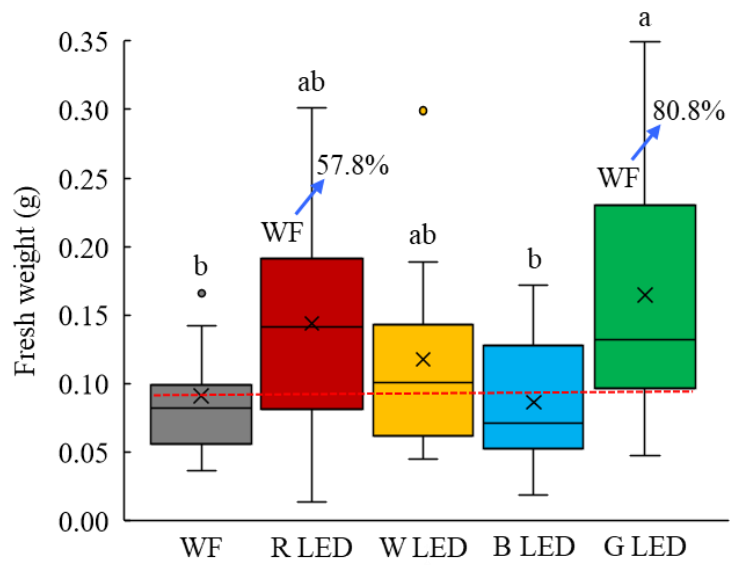

(b)

Figure 1. In vitro PLB organogenesis of D. okinawense under different LEDs on (a) Number of PLBs and (b) Fresh weight. WF, White fluorescent light; R, Red; W, White; B, Blue and G, Green. Crosses in the box represents the mean number of the newly regenerated PLB from the total explant cultured $(n=15)$. Blue arrow over the boxplot represents the percentage of increase over control (white fluorescent). Boxplots those share a letter are statistically identical, and those do not share are statistically different at Tukey's multiple comparisons test ( $\mathrm{p} \leq 0.05)$.

Table 1. Number of shoots regenerated from different culture conditions and media manipulation.

(A) Different LEDs, PCIB concentrations and HMI concentrations.

\begin{tabular}{|c|c|c|c|c|c|}
\hline LEDs & Shoots & PCIB (mg/L) & Shoots & $\mathrm{HMI}(\mathrm{ml} / \mathrm{L})$ & Shoots \\
\hline WF & $0.40 \pm 0.27$ & 0 & $2.07 \pm 0.09$ & 0 & $0.47 \pm 0.17$ \\
\hline R LED & $0.93 \pm 0.50$ & 0.01 & $2.87 \pm 1.32$ & 0.001 & $0.60 \pm 0.32$ \\
\hline W LED & $0.67 \pm 0.33$ & 0.1 & $0.4 \pm 0.40$ & 0.01 & $0.67 \pm 0.21$ \\
\hline B LED & $0.40 \pm 0.19$ & 1 & $0.67 \pm 0.46$ & 0.1 & $0.20 \pm 0.14$ \\
\hline G LED & $0.67 \pm 0.41$ & 10 & $0.27 \pm 0.27$ & & \\
\hline
\end{tabular}

(B) Different LEDs by using $0.01 \mathrm{~g} / \mathrm{L}$ PCIB and $0.001 \mathrm{~g} / \mathrm{L}$ HMI in culture media.

\begin{tabular}{|c|c|c|c|}
\hline \multicolumn{2}{|c|}{ PCIB $(0.01 \mathrm{mg} / \mathrm{L})$} & \multicolumn{2}{|c|}{ HMI $(0.001 \mathrm{ml} / \mathrm{L})$} \\
\hline LEDs & Shoots & LEDs & Shoots \\
\hline WF & $0.33 \pm 0.21$ & WF & NS \\
\hline R LED & $0.47 \pm 0.24$ & R LED & $0.13 \pm 0.09$ \\
\hline W LED & $0.67 \pm 0.25$ & W LED & $0.13 \pm 0.09$ \\
\hline B LED & $0.60 \pm 0.27$ & B LED & $0.20 \pm 0.12$ \\
\hline G LED & $1.53 \pm 0.88$ & G LED & $0.47 \pm 0.26$ \\
\hline
\end{tabular}

Here, data represents as the mean numbers \pm SE from the total explant cultured $(n=15)$, NS, No shoot.

The shoot formation rate for the all LEDs was similar and that was 26.7\% (Table 2A). On the other hand, the PLB formation rate was $100 \%$ for all light condition except blue LED (Table 2A). These results suggested that red and green LED can act as stimulus for the in vitro PLBs culture of D. okinawense while blue LED arrested their organogenesis.

Table 2. PLBs and shoot formation rate in percentage (\%). 
(2A) Different LEDs and various concentrations of PCIB (mg/L) and HMI (ml/L).

\begin{tabular}{|c|c|c|c|c|c|c|c|c|}
\hline LEDs & PLBs & Shoot & PCIB & PLBs & Shoot & HMI & PLBs & Shoot \\
\hline WF & 100.0 & 20.0 & 0 & 100.0 & 40.0 & 0 & 86.7 & 40.0 \\
\hline R LED & 100.0 & 26.7 & 0.01 & 100.0 & 40.0 & 0.001 & 86.7 & 26.7 \\
\hline W LED & 93.0 & 26.7 & 0.1 & 100.0 & 6.7 & 0.01 & 93.9 & 53.3 \\
\hline B LED & 80.0 & 26.7 & 1 & 86.7 & 13.3 & 0.1 & 60.0 & 13.3 \\
\hline G LED & 100.0 & 26.7 & 10 & 93.3 & 6.7 & & & \\
\hline
\end{tabular}

(2B) Different LEDs by using $0.01 \mathrm{~g} / \mathrm{L}$ PCIB and $0.001 \mathrm{~g} / \mathrm{L}$ HMI in culture media.

\begin{tabular}{lccllcc}
\hline \multicolumn{3}{c}{ PCIB $(0.01 \mathrm{mg} / \mathrm{L})$} & & \multicolumn{3}{c}{ HMI $(0.001 \mathrm{ml} / \mathrm{L})$} \\
\cline { 1 - 3 } \cline { 5 - 7 } LEDs & PLBs & Shoot & & LEDs & PLBs & Shoot \\
\cline { 1 - 2 } \cline { 5 - 7 } WF & 100.0 & 20.0 & & WF & 100.0 & NS \\
R LED & 93.3 & 26.7 & & R LED & 73.3 & 13.3 \\
W LED & 86.7 & 40.0 & & W LED & 46.7 & 13.3 \\
B LED & 86.7 & 33.3 & & B LED & 100.0 & 6.7 \\
G LED & 100.0 & 33.3 & & G LED & 93.3 & 20.0 \\
\hline
\end{tabular}

Here, data represents as percentage from the total explant cultured $(n=15)$.

\subsection{Putative anti-auxin, PCIB for PLB organogenesis of D. okinawense}

We used four different concentrations of PCIB for the organogenesis of PLB of $D$. okinawense and these were $0.01,0.1,1.0$ and $10 \mathrm{mg} / \mathrm{L}$ whereas we did not used any PCIB (0 $\mathrm{mg} / \mathrm{L})$ as control. We found that low concertation of PCIB $(0.01 \mathrm{mg} / \mathrm{L})$ significantly increase the number of PLB and fresh weight of newly generated PLBs, while the subsequent increase of the PCIB concentration $(0.1,1.0$ and $10 \mathrm{mg} / \mathrm{L})$ directed to the reduction of their organogenesis (Figure 2a).

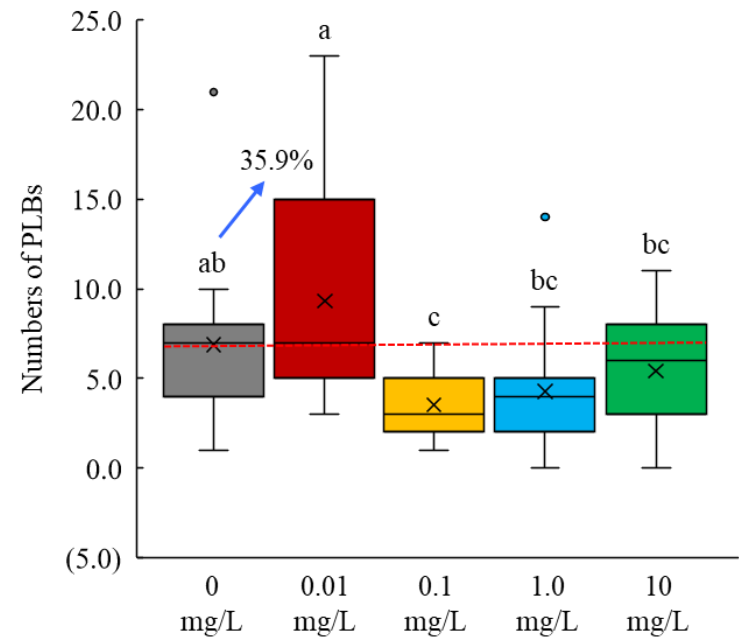

(a)

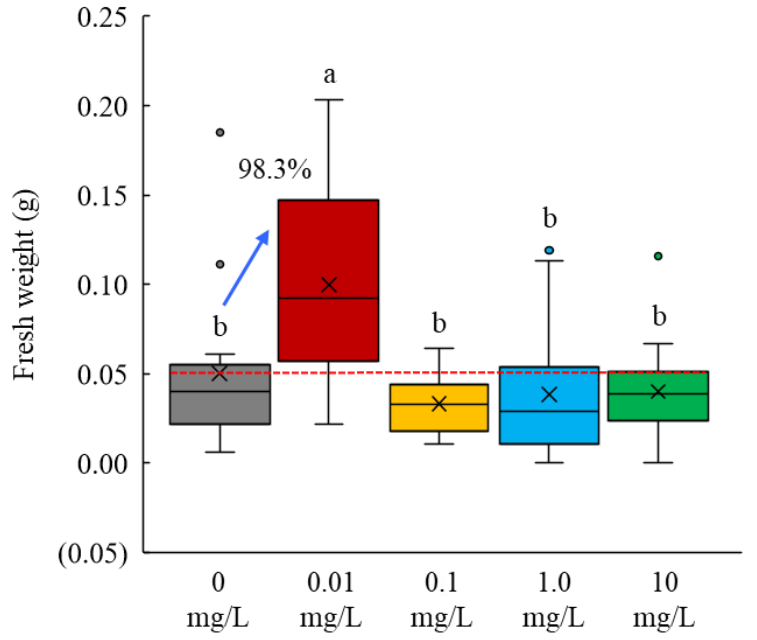

(b)

Figure 2. PLBs organogenesis of D. okinawense in the culture media using different concentration of PCIB (a) Effect on number of PLB regeneration and (b) Effect on their fresh weight. Crosses in the box represents the mean number of the newly regenerated PLB from the total explant cultured $(n=15)$. Blue arrow over the boxplot represents the percentage of increase over control $(0 \mathrm{mg} / \mathrm{L})$. Boxplots those share a letter are statistically identical, and those do not share are statistically different at Tukey's multiple comparisons test $(\mathrm{p} \leq 0.05)$. 
Addition of the $0.01 \mathrm{mg} / \mathrm{L}$ PCIB in culture media surpassed 35.9\% for numbers of PLB and $98.3 \%$ for their fresh weight over control (Figure $2 \mathrm{~b}$ ). Both the number of PLBs and their fresh weigh were dramatically decreased by the increase of the PCIB concentrations (Figure 2). We found 9.3 PLBs per explant by the application of $0.01 \mathrm{mg} / \mathrm{L} \mathrm{PCIB}$ with $0.10 \mathrm{~g}$ of their average fresh weight (Figure 2). The average number of shoots were also higher in the $0.01 \mathrm{mg} / \mathrm{L}$ of the PCIB (2.9 shoots per explant) treated culture media which was close to the control (2.1 shoots per explant) (Table 1A). The formation rate of PLB was $100 \%$ in $0,0.01$ and $0.1 \mathrm{mg} / \mathrm{L}$ of the PCIB, whereas the shoot formation rate was also higher for 0 and $0.1 \mathrm{mg} / \mathrm{L}$ over the other concentrations (Table 2A). Current result suggested us, addition of the low concentration of $p$-Chlorophenoxy Isobutyric acid can be acted as stimulus for the in vitro culture of D. okinawense.

\subsection{An antifungal agrochemical, HMI for PLB organogenesis of D. okinawense}

We used three different concentrations of Tachigaren (or, HMI) with control for the PLB organogenesis of D. okinawense (Figure 3).
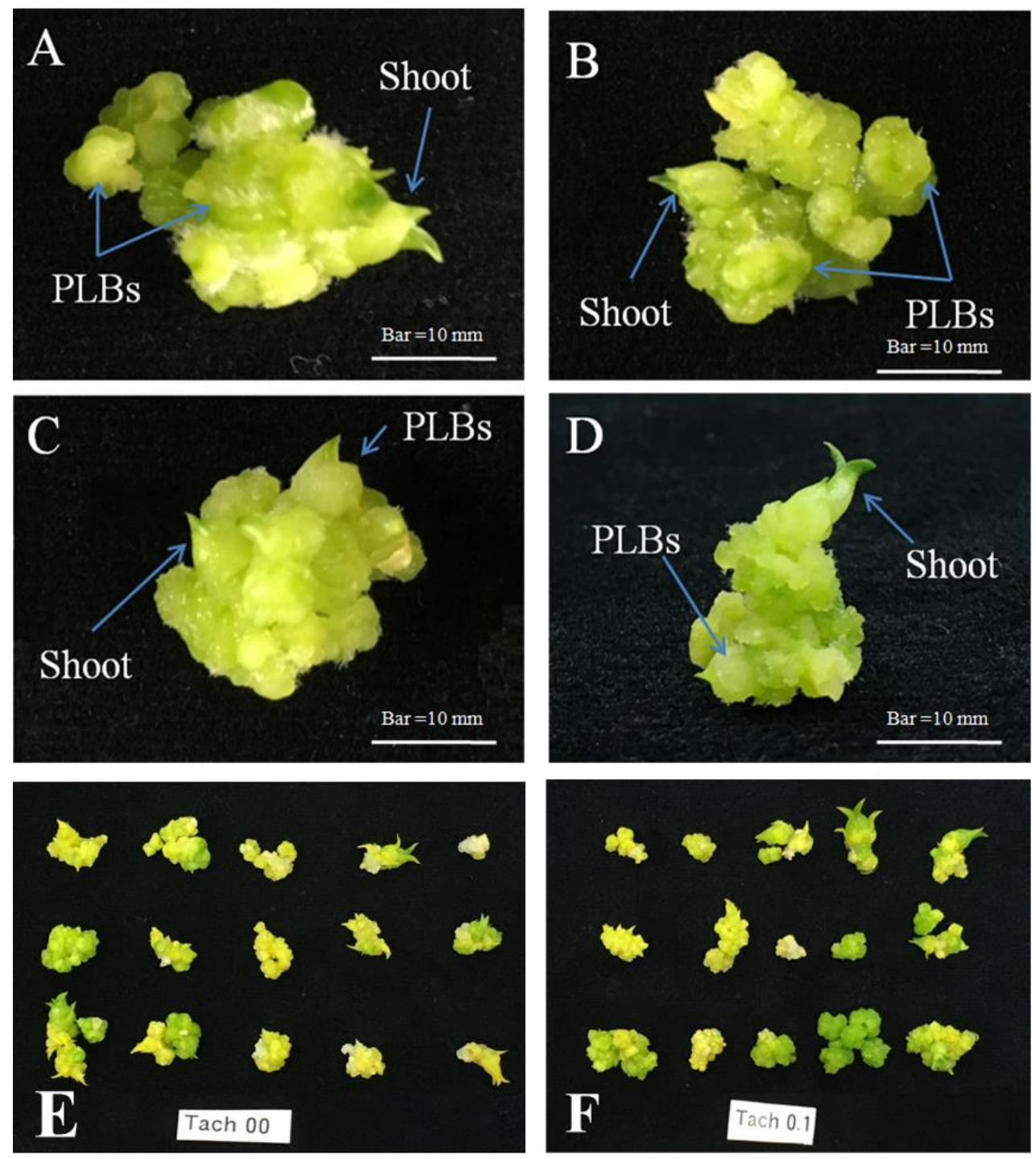

Figure 3. Formation of PLB and shoot of D. okinawense at different concentrations of HMI (A-D from single PLB) A; 0 ml/L (Control), B; $0.01 \mathrm{ml} / \mathrm{L}, \mathrm{C} ; 0.1 \mathrm{ml} / \mathrm{L}, \mathrm{D} ; 1.0 \mathrm{ml} / \mathrm{L}$ of HMI, E; newly generated PLBs in control from the fifteen mother PLBs, F; newly generated PLBs in $0.1 \mathrm{ml} / \mathrm{L}$ from the fifteen mother PLBs. 
Addition of very low concentration of Tachigaren $(0.01 \mathrm{ml} / \mathrm{L})$ significantly surpassed 19.3\% number of PLB formation (Figure 4a). We found maximum 4.5 PLB per explant from the culture media treated with $0.01 \mathrm{ml} / \mathrm{L}$ HMI (Figure $4 \mathrm{a}$ ) while we did not find any significant variation in average fresh weight and number of newly generated shoot (Figure $4 \mathrm{~b}$, Table 1A). Application of very low concentrations of Tachigaren can able to increase the numbers of PLB of D. okinawense.

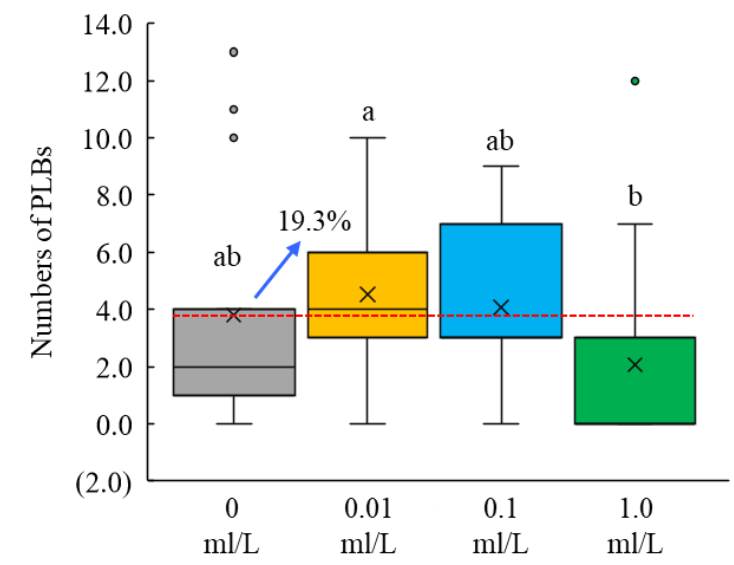

(a)

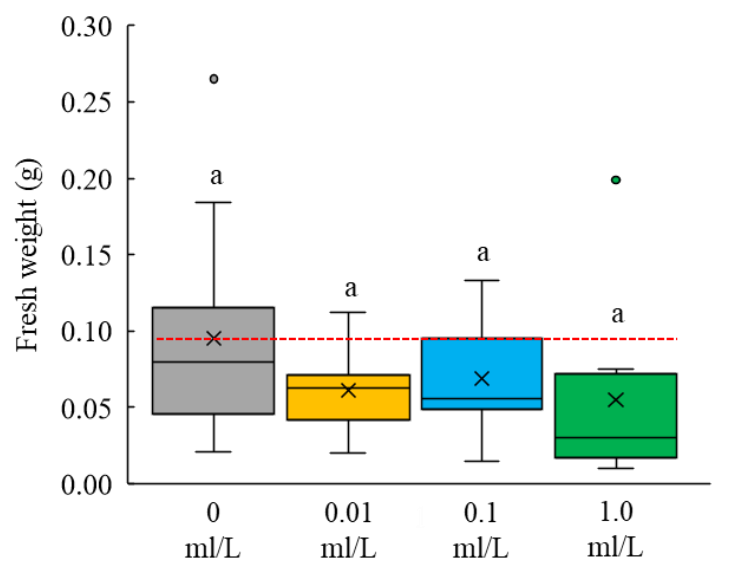

(b)

Figure 4. Response of different concentrations of HMI (or Hymexazol or, Tachigaren) for the PLBs organogenesis of $D$. okinawense on the number of PLB regeneration (a) and fresh weight (b). Crosses in the box represents the mean number of the newly regenerated PLB from the total explant cultured $(\mathrm{n}=15)$. Blue arrow over the boxplot represents the percentage of increase over control $(0 \mathrm{mg} / \mathrm{L})$. Boxplots those share a letter are statistically identical, and those do not share are statistically different at Tukey's multiple comparisons test $(\mathrm{p} \leq 0.05)$.

\subsection{Effect of LEDs on PCIB and HMI manipulated culture media for the PLB organogenesis of D. okinawense}

We found that low concentration of PCIB $(0.01 \mathrm{mg} / \mathrm{L})$ and HMI $(0.01 \mathrm{ml} / \mathrm{L})$ had the significant effect on in vitro PLB organogenesis of $D$. okinawense. We have further analyzed the effect of four different LEDs for PLB organogenesis of D. okinawense using the PCIB $(0.01 \mathrm{mg} / \mathrm{L})($ Figure 5$)$ and HMI $(0.01 \mathrm{ml} / \mathrm{L})$ manipulated culture media.

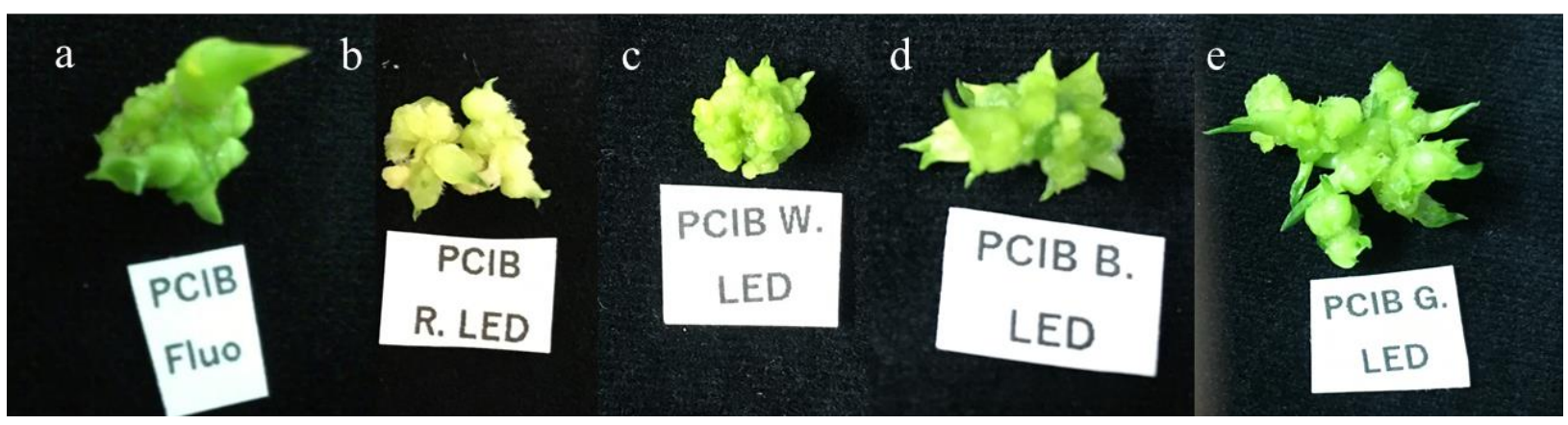

Figure 5. PLBs and shoot of D. okinawense regenerated from $0.01 \mathrm{mg} / \mathrm{L}$ PCIB manipulated culture media under different LEDs, (a) white fluorescent light, (b) red LED, (c) white LED, (d) blue LED and (e) green LED.

Our PCIB and HMI manipulated culture media did not show any noticeable increase of the numbers of PLBs when they were cultured under red, white and blue LED. Under both white and red LED, PCIB and HMI was negatively affected the PLB regeneration and decrease the number of PLBs compared to the control. Interestingly, PCIB and HMI 
manipulated culture media was tended to influence to the PLBs regeneration under blue LED but the number of PLBs was not cross to the white fluorescent light (Figure 6).

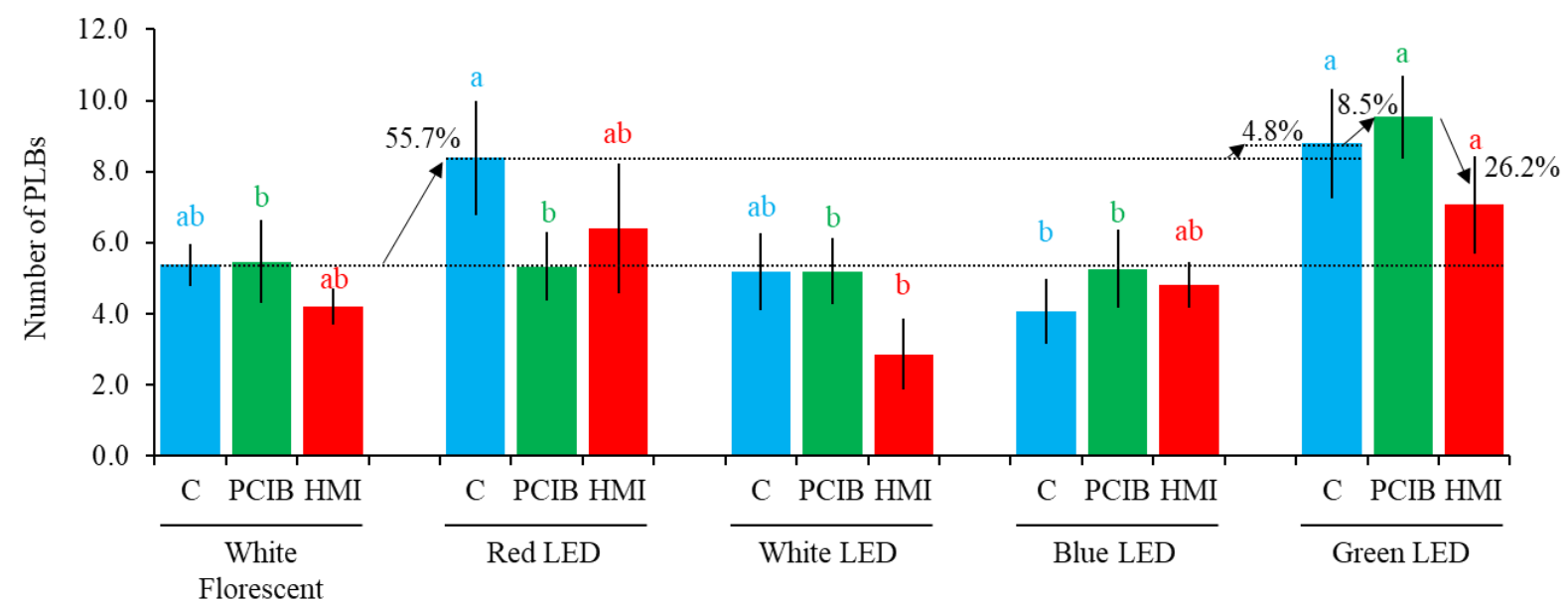

Figure 6. Numbers of newly generated PLBs of D. okinawense under different LEDs using PCIB and HMI manipulated culture media. Blue, green and red bar represents non-manipulated culture media (C), $0.01 \mathrm{mg} / \mathrm{L}$ PCIB manipulated culture media (PCIB) and $0.01 \mathrm{mg} / \mathrm{L}$ HMI manipulated culture media (HMI), respectively (total number of explants, $n=15)$. Upward arrows over the boxplot represents the percentage of increase or downward arrow represents the percentage of decrease. Letters above the bars that share are statistically identical, and those do not share are statistically different at $\mathrm{p} \leq 0.05$ by Tukey's multiple comparisons (comparison for the significance - only between the same color letters.

We found that red LED surpassed 55.7\% over white fluorescent light which was further $4.8 \%$ surpassed by green LED compared to non-manipulated culture media under red LED (Figure 6). We found the noticeable effect under green LED. Both PCIB and HMI showed positive response for the increasing numbers of PLB of D. okinawense under green LED. Green LED produced 8.8 PLB per explant, but the addition of $0.01 \mathrm{mg} / \mathrm{L}$ of PCIB in culture media can surpassed 8.5\% more PLBs (9.5 PLB per explant) under green LED (Figure 6). HMI (0.01 ml/L) manipulated culture media under green LED showed the tendency to increase the number of PLB but the final number of PLB was 26.2\% lower (7.1 PLB per explant) compared to the $0.01 \mathrm{mg} / \mathrm{L}$ of PCIB manipulated culture media under green LED (Figure 6). Red LED surpassed $44.3 \%$ fresh weight $(0.137 \mathrm{gm})$, our PCIB and HMI manipulated culture media were also tended to increase fresh weight under red LED compared to the fluorescent light (Figure 7).

Green LED exceeded 18.9\% fresh weight compared to red LED culture media over nonmanipulated culture media under red LED; and we also found 6.9\% and $14.6 \%$ surpass of the fresh weight respectively by the manipulation of $0.01 \mathrm{mg} / \mathrm{L}$ of PCIB and $0.01 \mathrm{ml} / \mathrm{L}$ of HMI (Figure 7). Culture media with $0.01 \mathrm{mg} / \mathrm{L}$ of PCIB and $0.01 \mathrm{mg} / \mathrm{L} \mathrm{HMI}$ produced maximum number of shoots (1.53 and 0.47 per explants) under green LED compared to other treatments (Table 1B), and the formation rate of PLB and shoot have been mentioned in Table 2B. 


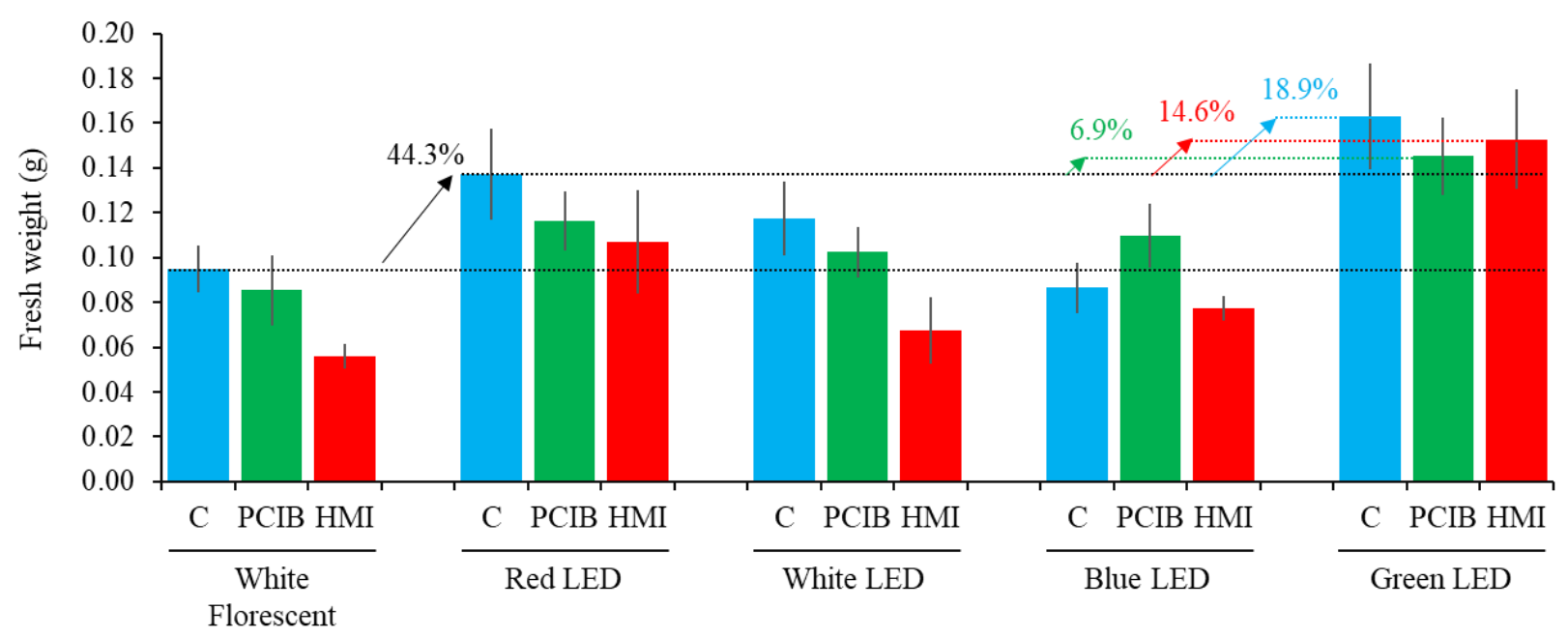

Figure 7. Numbers of newly generated PLBs of D. okinawense under different LEDs using PCIB and HMI manipulated culture media. Blue, green and red bar represents non-manipulated culture media (C), $0.01 \mathrm{mg} / \mathrm{L}$ PCIB manipulated culture media (PCIB) and $0.01 \mathrm{mg} / \mathrm{L}$ HMI manipulated culture media (HMI), respectively (total number of explants, $n=15$ ). Upward arrows over the boxplot represents the percentage of increase. Letters above the bars those shares are statistically identical, and those do not share are statistically different at $\mathrm{p} \leq 0.05$ by Tukey's multiple comparisons (comparison for the significance - only between the same color letters).

\section{Discussion}

MS medium [45] is usually used in micro-propagation for diverse orchid including Dendrobium genus $[46,47]$. But addition of the any growth chemicals can accelerate the plant micro-propagation and PLB organogenesis as well. Sucrose is widely accepted for diverse plant species as the major carbohydrate source to supply the energy to cells in plant tissue culture media [48]. Concentration of sucrose also plant specific for micropropagation, while $20 \mathrm{~g} / \mathrm{L}$ sucrose is used orchid tissue culture [31,38,49-51], and we confirmed that use of $20 \mathrm{~g} / \mathrm{L}$ of sucrose can be efficient for the PLB organogenesis of D. okinawense similar to any other Dendrobium sp. (Supplementary Table S1) [6,7]. Sucrose is needed in plant embryo to increase cell division, and encouraging cell expansion [52]. Ideal concentration of sucrose is important for the micro-propagation, because sucrose deficiency/oversupply can be detrimental to plant cell growth in vitro. We also found the lower PLBs regenerations of D. okinawense by the very high or, low concentration of sucrose (Supplementary Table S1). Lower sucrose hampers the carbon supplies to the in vitro explant, whereas high sugar concentration can lead to osmotic stress conditions or, excessive carbohydrate accumulation and ultimately hamper photosynthesis process [53]; thus, may resulted low PLBs organogenesis of $D$. okinawense.

Light is an signaling component that controls plant morphology, physiology and development in plant growth, it is also a regulating factor for in vitro plant growth and development [54-59]. Excessive light can lead to the cells damage during in vitro plant propagation [60,61]. Light emitting diodes (LED) are more effective over the traditional fluorescent light, but it is also plant specific [62]. In this study, we identified the specific monochromatic LED for the in vitro PLB organogenesis of D. okinawense. Generally, plant respond well to red and blue LED while green LED hardly ever consider for their biomass growth; because red and blue wavelengths are strongly absorbed by chlorophyll $a$ and $b$ [23]. D. okinawense showed highest efficient PLB regeneration under green LED and thereafter red LED, while PLB organogenesis of $D$. okinawense negatively responded under blue LED (Figure 1, Figure 6, Figure 7, Table 1). Optimistic and undesirable PLB organogenesis of the D. okinawense respectively under green and blue LED indicated the plant specificity for micro-propagation to dissimilar monochromatic light. However, we did not check the monochromatic light combination for the PLB organogenesis of D. okinawense, and that may have the possibility for the further improvement of the PLB organogenesis. Previous 
studies also reported the efficiency of PLB organogenesis under the combination of the different monochromatic light [2,3,38]. Effectiveness of red and blue light is well known, while very few studies reported about the efficacy of the green light. Green LEDs has the discrete effects on plant biology [63], and the specific mechanisms of green light has not been identified yet. Plants leaves appear as green that literally does not mean that plant reflected all green light, only $10-50 \%$ of green light is reflected by plant chloroplasts [23]. Rest of the green light has been absorbed by chlorophyll and carotenoid pigments and absorbed green light is also used for photosynthesis. The existence of the plant growth response to green light has also previously been found by some researchers $[64,65]$ but this response is not easily attributed to the currently known suite of light receptors $[63,66]$. Green wavelength can penetrate to the plant canopy; it can drive and regulate different plant physiological process, stimulate photosynthesis, contribute to carbon gain and ultimately lead to more biomass production [23,67]. Green wavelengths cannot be ignored in LED-based in vitro plant propagation or crop cultivation in horticulture.

PCIB plays an important role in plant growth and development by auxin perception and signal transduction due to their auxin-induced physiological responses inhibition characters [11,12]. Application of exogenous auxin can promote PLB growth, shoot and root formation; while auxin in conjunction with cytokinins can also promote PLBs organogenesis, shoot regeneration and callus formation as well $[15,68]$. We found that addition of very low concentration of PCIB $(0.01 \mathrm{mg} / \mathrm{L})$ in MS medium in vitro greatly enhanced the organogenesis of PLB of $D$. okinawense as well as their fresh weight and number of shoots (Figure 2). On the other hand, when the application of PCIB more than the concentration of $0.01 \mathrm{mg} / \mathrm{L}$, the organogenesis of D. okinawense were decreased in each aspect and which were even lower than control (Figure 2). This study revealed that the application of low concentration of PCIB can play a role for in vitro PLBs organogenesis of $D$. okinawense. We have also noticed that manipulated culture media with $0.01 \mathrm{mg} / \mathrm{L}$ of PCIB even better for the PLB organogenesis under green LED compared with the fluorescent light (Figure 6). It suggests us PCIB is more effective for the PLB organogenesis in combination with other factors such as green LED (our findings) and ABA [69]. Fungal contamination is a serious problem in micro-propagation, and different toxic chemicals such as sodium hypochlorite $(\mathrm{NaOCl})$ or, mercury chloride $\left(\mathrm{HgCl}_{2}\right)$ are used to disinfect plant materials. We used Tachigaren (HMI) in culture media for the PLB organogenesis of $D$. okinawense. Tachigaren is an antifungal agent that can control the fungal growth, and additionally it can regulate plant growth and development by increasing auxin activity [16]. We found that very low concentration of HMI $(0.001 \mathrm{ml} / \mathrm{L})$ in culture media increases the number of PLBs over control. The PLBs organogenesis was chronologically decrease with the increases of HMI concentration; and at high HMI concentration $(1 \mathrm{ml} / \mathrm{L})$, the PLBs numbers were even lower than control (Figure 3). The $0.001 \mathrm{ml} / \mathrm{L} \mathrm{HMI}$ manipulated culture media 4.2 to 4.5 PLB per explant whereas the number of PLB increased in 7.1 per explant under green LED (Figure 3 and Figure 4). Tachigaren was also found to be more effective in aggregation with another factor such as green LED for the in vitro PLB organogenesis in D. okinawense.

\section{Materials and methods}

\subsection{Preparation of explants, culture media and conditions}

We generated PLBs (Protocorm-like bodies) of D. okinawense, and multiplied in the modified Murashige and Skoog (MS) medium [70] by transferring new medium in every two months. We used ammonium nitrate $(412.5 \mathrm{mg} / \mathrm{L})$ and potassium nitrate $(950.0 \mathrm{mg} / \mathrm{L})$ to modify the MS medium. We used $20 \mathrm{~g} / \mathrm{L}$ sucrose (Sigma-Aldrich ${ }^{\circledR}$, Tokyo, Japan) in culture media, and $2.2 \mathrm{~g} / \mathrm{L}_{\text {Phytagel }}{ }^{\mathrm{TM}}$ (Sigma-Aldrich ${ }^{\circledR}$, Tokyo, Japan) were used to solidify the culture medium. We adjusted the $\mathrm{pH}$ at 5.5-5.8 using $1 \mathrm{mM} 2$-(N-morpholino) ethanesulfonic acid sodium salt (MES-Na) prior to autoclaving at $121^{\circ} \mathrm{C}$ for $15 \mathrm{~min}$ at 117.1 $\mathrm{KPa}$. We used $50 \mathrm{ml}$ of culture media in $250 \mathrm{ml}$ culture bottle (UM culture bottle: AsOne, Japan) for the preparation of explants. We used each single PLBs as explants. 


\subsection{Manipulation of the culture media and environment}

We regenerated the PLBs under four different LEDs (white, red, blue and green) with white fluorescent tube as control. The wavelengths of these LEDs were as follows, blue $(420-550 \mathrm{~nm})$, red $(580-670 \mathrm{~nm})$, white $(420-750 \mathrm{~nm})$ and green $(460-610 \mathrm{~nm})$. We also manipulated the culture media by the different concentrations of a putative anti-auxin PCIB $(0,0.01,0.1,1$ and $10 \mathrm{mg} / \mathrm{L})$ (Sigma-Aldrich ${ }^{\circledR}$, Tokyo, Japan), and an antifungal agent HMI $(0,0.01,0.1$, and $1.0 \mathrm{ml} / \mathrm{L})$ (Tachigaren ${ }^{\mathrm{TM}}$, first launched by Sankyo Co. Ltd.; and currently as Mitsui Chemicals Agro, Inc., Tokyo, Japan). We sorted out the best concentration for PLB multiplication both for PCIB and HMI. We again manipulate the culture media by the best concentration of PCIB and HMI independently, and then cultured under previously mentioned four different LEDs. We used $30 \mathrm{ml}$ of culture media in $250 \mathrm{ml}$ culture bottle and 3 bottles for each treatment, we inoculated 5 explants in each bottle and cultured for 42 days in every point of examination.

\subsection{Data collection and analysis}

We counted the numbers of PLBs, numbers of shoots and measured their fresh weight. We counted the mature and well developed PLBs only, and we did not count the newly emerge and tiny PLBs (Figure 3A-D). The average numbers and percentages of PLBs and shoots were calculated as follows.

Average number $=$ Number of cultured explants with new PLB/total number of culture explants

$\%$ of PLB $=($ Number of the cultured explants with new PLBs/total number of cultured explants) $X 100$

The data were statistically analyzed by one-way ANOVA using R (https://www.Rproject.org/) by Tukey's multiple comparisons test at 95\% confidence interval.

\section{Conclusion}

In general, plants are more responsive under red and blue light for the in vitro propagation. Like the universal knowledge for the in vitro plant propagation, we also found red LEDs as a promoting factor for in vitro PLB organogenesis of D. okinawense. Interestingly, we found green LED instead of blue LED as a promoting factor for PLB growth in D. okinawense. We cannot disregard the lesser influencing green LED for the plant micropropagation specifically in PLB regeneration of orchids, however effect of monochromatic light it can be species specific. Very low concentration of PCIB or HMI in culture media can accelerate PLB organogenesis of D. okinawense which can further surplus in aggregation with monochromatic green or red light. Our results suggested that green LED in conjunction with low concentration of putative anti-auxin (PCIB) or antifungal agent (HMI) can be $60-70 \%$ more effective for the PLBs regenerations of D. okinawense compared to usual application of red or blue LED. Our current finding will help us to conserve endangered epiphytic orchid D. okinawense by their rapid PLBs organogenesis. However, for the development of the most efficient PLBs organogenesis of D. okinawense, we need more study using diverse growth promotors, growth inhibitors, elicitors, and their combinations in conjugation with dissimilar LEDs specifically green and red LED.

Supplementary Materials: The following are available online at www.mdpi.com/xxx/s1, Table S1. Effectiveness of different concentrations of sucrose for PLB organogenesis of D. okinawense.

Author Contributions: Conceptualization, H.Mb. and K.S.; materials acquisition, K.S.; methodology and validation, H.Mb.; formal analysis, H.Mb. and H.M.; writing - original draft preparation, H.Mb. and H.M.; writing - review and editing, H.Mb., K.S. and H.M.

Funding: "This research had not any external funding". 
Acknowledgments: We thank Dr. Sultana Umma Habiba for her technical comments to improve the manuscript. We also thank to the members of the Laboratory of Vegetable and Floricultural Science, Kochi University for their assist during material materials acquisition and sub-culture.

Conflicts of Interest: "The authors declare no conflict of interest."

\section{References}

1. Park, S.Y.; Huh, Y.S.; Paek, K.Y. Common protocols in orchid micropropagation. In Orchid propagation: From laboratories to greenhouses - methods and protocols, Springer protocols handbooks, 1st ed.; Lee, Y.I., Yeung, E.C.-T., eds.; Humana Press: New York, USA, 2018, pp 1-524.

2. Roberto, S.R.; Colombo, R.C. Innovation in propagation of fruit, vegetable and ornamental plants. Horticulturae $2020,6,23$.

3. Cardoso, J.C.; Zanello, C.A.; Chen, J.-T. An overview of orchid protocorm-like bodies: Mass propagation, biotechnology, molecular aspects, and breeding. Int. J. Mol. Sci. 2020, 21, 985.

4. Chugh, S.; Guha, S.; Rao, U. Micropropagation of orchids: A review on the potential of different explants. Sci. Hortic. 2009, 122, 507-520.

5. Cui, H.-Y.; Murthy, H.N.; Moh, S.H.; Cui, Y.; Lee, E.-J.; Paek, K.-Y. Protocorm culture of Dendrobium candidum in balloon type bubble bioreactors. Biochem. Eng. J. 2014, 88, 26-29.

6. Habiba, S.U.; Shimasaki, K.; Ahsan, M.M.; Alam, M.M. Effects of different light quality on growth and development of protocorm like bodies (PLBs) in Dendrobium kingianum cultured in vitro. Bangladesh Res. Pub. J. 2014, 10, $223-227$.

7. Habiba, S.U.; Shimasaki. K.; Ahsan, M.M.; Alam, M.M. Effect of 6-benzylaminopurine (BA) and hyaluronic acid (HA) under white light emitting diode (LED) on organogenesis in protocorm-like bodies (PLBs) of Dendrobium kingianum. American-Eurasian J. Agric. Environ. Sci. 2014, 14, 605-609.

8. Parthibhan, S.; Rao, M.V.; Kumar, T.S. In vitro regeneration from protocorm in Dendrobium aqueum Lindley - An imperiled orchid. J. Genet. Eng. Biotechnol. 2015, 13, 227-233.

9. Chung, S.; Lu, S. Dendrobium okinawense Hatusima \& Ida (Orchidaceae): A newly recorded species in Taiwan. Taiwania 2007, 52, 106-112.

10. Hatsushima, S.; Ida, R. A new Dendrobium from Isl. Okinawa. J. Geobot. 1970, 18, 77-79.

11. Kim, S.-K.; Chang, S.C.; Lee, E.J.; Chung, W.-S.; Kim, Y.-S.; Hwang, S.; Lee, J.S. Involvement of brassinosteroids in the gravitropic response of primary root of maize. Plant Physiol. 2000, 123, 997-1004.

12. Xie, Q.; Frugis, G.; Colgan, D.; Chua, N.H. Arabidopsis NAC1 transduced auxin signal downstream of TIR1 to promote lateral root development. Genes Dev. 2000; 14, 3024-3036.

13. Burström, H. Studies on growth and metabolism of roots. IV. Positive and negative auxin effects on cell elongation. Physiol. Plant 1950, 3, 277-292.

14. MacRae, D.H.; Bonner, J. Chemical structure and antiauxin activity. Physiol. Plant 1953, 6, 485-510.

15. Novak, S.D.; Luna, L.J.; Gamage, R.N. Role of auxin in orchid development. Plant Signal Behav. 2014, 9, e2972277.

16. Ota, Y. Plant growth-promoting activities of 3-hydroxy-5-methyl-isoxazole. Jpn. Agric. Res. Q. 1975, 9, 1-7.

17. Harveson, R.M.; Windels, C.E.; Smith, J.A.; Brantner, J.R.; Cattnach, A.W.; Giles, J.F.; Hubbell, L.; Cattnach, N.R. Fungicide registration and a small niche market: a case history of hymexazol seed treatment and the U.S. sugar beet industry. Plant Dis. 2007, 91, 780-790.

18. Yan, L.; Yukun, Q.; Song, L.; Pengcheng, L.; Rong'e, X. Preparation, characterization, and antifungal activity of hymexazollinked chitosan derivatives. Chin. J. Ocean. Limnol. 2017, 35, 1079-1085.

19. Amaki, W.; Yamazaki, N.; Ichimura, M.; Watanabe, H. Effects of light quality on the growth and essential oil content in sweet basil. Acta Hortic. 2011, 907, 91-94.

20. Brazaitytè, A.; Virsilè, A.; Samuolienè, G.; Jankauskienė, J.; Sakalauskienė, S.; Sirtautas, R.; Novičkovas, A.; Dabasinskas, L.; Vastakaite, V.; Miliauskienè, J.; Duchovskis, P. Light quality: Growth and nutritional value of microgreens under indoor and greenhouse conditions. Acta Hortic. 2016, 1134, 277-284.

21. Bugbee, B. Toward an optimal spectral quality for plant growth and development: the importance of radiation capture. Acta Hortic. 2016, 1134, 1-12.

22. Silva, S.T.; Bertolucci, S.K.V.; da Cunha, S.H.B.; Lazzarini, L.E.S.; Tavares, M.C.; Pinto, J.E.B.P. Effect of light and natural ventilation systems on the growth parameters and carvacrol content in the in vitro cultures of Plectranthus amboinicus (Lour.) Spreng. Plant Cell Tiss. Org. 2017, 129, 501-510.

23. Smith, H.L.; McAusland, L.; Murchie, E.H. Don't ignore the green light: exploring diverse roles in plant processes. J. Exp. Bot. 2017, 68, 2099-2110.

24. Li, H.; Tang, C.; Xu, Z.; Liu, X.; Han, X. Effects of different light sources on the growth of non-heading Chinese cabbage (Brassica campestris L.). J. Agric. Sci. 2012, 4, 262-270.

25. Naznin, M.T.; Lefsrud, M.; Gravel, V.; Azad, M.O.K. Blue light added with red LEDs enhance growth characteristics, pigments content, and antioxidant capacity in lettuce, spinach, kale, basil, and sweet pepper in a controlled environment. Plants, 2019, 8 , 93.

26. Johkan, M.; Shoji, K.; Goto, F.; Hahida, S.; Yoshihara, T. Effect of green light wavelength and intensity on photomorphogenesis and photosynthesis in Lactuca sativa. Environ. Expt. Bot. 2012, 75, 128-133. 
27. Samuolienè, G.; Brazaitytė, A.; Sirtautas, R.; Novičkovas, A.; Duchovskis, P. The effect of supplementary LED lighting on the antioxidant and nutritional properties of lettuce. Acta Hortic. 2012, 952, 835-841.

28. Samuolienè, G.; Sirtautas, R.; Brazaitytè, A.; Duchovskis, P. LED lighting and seasonality effects antioxidant properties of baby leaf lettuce. Food Chem. 2012, 134, 1494-1499.

29. Stutte, G.W.; Edney, S.; Skerritt, T. Photoregulation of bioprotectant content of red leaf lettuce with light-emitting diodes. HortScience 2009, 44, 79-82.

30. Li, Q.; Kubota, C. Effects of supplemental light quality on growth and phytochemicals of baby leaf lettuce. Environ. Expt. Bot. 2009, 67, 59-64.

31. Kaewjampa, N.; Shimasaki, K. Effects of green LED lighting on organogenesis and superoxide dismutase (SOD) activities in protocorm-like bodies (PLBs) of Cymbidium cultured in vitro. Environ. Control. Biol. 2012, 50, 247-254

32. Nahar, S.J., Shimasaki, K., Haque, S.M. Effect of different light and two polysaccharides on the proliferation of protocrom-like bodies of Cymbidium cultured in vitro. Acta Hortic. 2012, 956, 307-313.

33. Nahar, S.J.; Shimasaki, K.; Haque, S.M. Chondroitin sulfate can be a new plant growth regulator for Cymbidium micropropagation@. Acta Hortic. 2013, 1014, 449-455.

34. Nahar, S.J.; Haque, S.M.; Shimasaki, K. Organogenesis of Cymbidium finlaysonianum under different sources of lights. AmericanEurasian J. Agric. Environ. Sci. 2015, 15, 2095-2101.

35. Kamal, M.M.; Shimasaki, K.; Akhter, N. Effect of light emutting diode (LED) lamps and N-Acetyleglucoseamine (NAG) on organogenesis in protocorm-like-bodies (PLBs) of Cymbidium hybrid cultured In Vitro. Plant Tissue Cult. Biotech. 2014, 24, 273277.

36. Sultana, K.S.; Hasan, K.M.; Hasan, K.M.; Sultana, S.; Mehraj, H.; Shimasaki, K.; Habiba, S.U. Effect of hyaluronic acid (HA) on organogenesis in protocorm-like-bodies (PLBs) of Phalaenopsis 'Fmk02010' cultured in vitro. American-Eurasian J. Agric. Environ. Sci. 2015, 15, 1721-1724.

37. Sultana, K.S.; Hasan, K.M.; Hasan, K.M.; Sultana, S.; Mehraj, H.; Shimasaki, K.; Habiba, S.U. Effect of two elicitors on organogenesis in protocorm-like bodies (PLBs) of Phalaenopsis 'Fmk02010' cultured in vitro. World Appl. Sci. J. 2015, 33, 1528-1532.

38. Mehraj, H.; Alam, M.M.; Habiba, S.U.; Mehbub, H. LEDs combined with CHO sources and CCC priming PLB regeneration of Phalaenopsis. Horticulturae 2019, 5, 34.

39. Gupta, S.D.; Jatothu, B. Fundamentals and applications of light-emitting diodes (LEDs) in in vitro plant growth and morphogenesis. Plant Biotechnol. Rep. 2013, 7, 211-220.

40. Teixeira da Silva, J.A. The response of protocorm-like bodies of nine hybrid Cymbidium cultivars to light-emitting diodes. Environ. Exp. Biol. 2014, 12, 155-159.

41. Okinawa Prefecture. Threatened wildlife in Okinawa, 2nd ed. (Fungi and Plants); Red data Okinawa. Nature Conservation Division, Department of Cultural \& Environmental Affairs, Okinawa Prefectural Government, Naha, Japan. 2006, p. 251 (in Japanese). http://www.pref.okinawa.jp/site/kankyo/shizen/hogo/okinawa_rdb_kinrui_syokubutu.html

42. Kyushu Regional Environmental Office of Ministry of the Environment (MoE). Notice of a leaflet for transfer restrictions of Okinawa-Sekkoku (etc.), 2006. Available online: http://kyushu.env.go.jp/to_2006/0904a.html. URL (accessed on 23 ${ }^{\text {rd }}$ March 2021).

43. Ministry of the Environment (MoE). Threatened wildlife of Japan. Red data book 2014 (in Japanese), Gyosei Corporation: Tokyo, Japan, 2015, 8, p. 347.

44. Abe, S.; Kotaka, N.; Takashima, A.; Abe, T.; Saito, K.; Masaki, T. Host selection and distribution of Dendrobium okinawense, an endangered epiphytic orchid in Yambaru, Japan. Ecol Res. 2018, 33, 1069-1073.

45. Murashige, T.; Skoog, F. A revised medium for rapid growth and bio assays with tobacco tissue cultures. Physiol. Plant. 1962, $15,473-497$.

46. Martin, K.P.; Madassery, J. Rapid in vitro propagation of Dendrobium hybrids through direct shoot formation from foliar explants, and protocorm-like bodies. Sci. Hort. 2006, 108, 95-99.

47. Fadel, D.; Kintzios, S.; Economou, A.S.; Moschopoulou, G.; Constantinidou, H.I.A. Effect of different strength of medium on organogenesis, phenolic accumulation and antioxidant activity of spearmint (Mentha spicata I.). Open Hort. 2010, 3, 31-35.

48. Swamy, M.K.; Sudipta, K.M.; Balasubramanya, S.; Anuradha, M. Effect of different carbon sources on in vitro morphogenetic response of patchouli (Pogostemon cablin Benth.). J. Phytol. 2010, 2, 11-17.

49. de Faria, R.T.; Rodrigues, F.N.; Olivera, L.V.R.; Muller, C. In vitro Dendrobium nobile plant growth and rooting in different sucrose concentrations. Hortic. Bras. 2004, 22, 780-783.

50. Yoon, Y.J.; Murthy, H.N.; Hahn, E.J.; Paek, K.-Y. Biosmass production of Anoectochilus formosanus hayata in bioreactor system. J. Plant Biol. 2007, 50, 573-576.

51. Baque, M.A.; Shin, Y.-K.; Elshmari, T.; Lee, E.-J.; Paek, K.-Y. Effect of light quality, sucrose and coconut water concentration on the micropropagation of Calanthe hybrids ('Bukduseong' × 'Hyesung' and 'Chunkwang' × 'Hyesung'). Aust. J. Crop Sci. 2011, 5, 1247-1254.

52. Borisjuk, L.; Walenta, S.; Weber, H.; Rollerschek, H.; Mueller-Klieser, W.; Wobus. U. Spatial analysis of plant metabolism: Sucrose imaging within Vicia faba in cotyledons reveals specific developmental patterns. Plant J. 2003, 29, 521-530.

53. Chin, D.P.; Mishiba, K.; Mii, M. Agrobacterium-mediated transformation of protocorm-like bodies in Cymbidium. Plant Cell Rep. 2007, 26, 735-743.

54. Lin, Y.; Li, J.; Li, B.; He, T.; Chun, Z. Effects of light quality on growth and development of protocorm-like bodies of Dendrobium officinale in vitro. Plant Cell Tiss. Organ Cult. 2011, 105, 329-335. 
55. Azmi, N.S.; Ahmad, R.; Ibrahim, R. Fluorescent light (FL), red led and blue led spectrums effects on in vitro shoots multiplication. J. Teknol. 2016, 78, 93-97.

56. Manivannan, A.; Soundararajan, P.; Park, Y.G.; Wei, H.; Kim, S.H.; Jeong, B.R. Blue and red light-emitting diodes improve the growth and physiology of in vitro-grown carnations 'Green Beauty' and 'Purple Beauty'. Hortic. Environ. Biotechnol. 2017, 58, 1220.

57. Darko, E.; Heydarizadeh, P.; Schoefs, B.; Sabzalian, M.R. Photosynthesis under artificial light: the shift in primary and secondary metabolism. Philos. Trans. R. Soc. Lond B Biol. Sci. 2014, 369, 20130243.

58. Reis, A.; Kleinowski, A.M.; Klein, F.R.S.; Telles, R.T.; do Amarante, L.; Braga, E.J.B. Light quality on the in vitro growth and production of pigments in the genus Alternanthera. J. Crop Sci. Biotechnol. 2015, 18, 349-357.

59. Bantis, F.; Ouzounis, T.; Radoglou, K. Artificial LED lighting enhances growth characteristics and total phenolic content of Ocimum basilicum, but variably affects transplant success. Sci. Hort. 2016, 198, 277-283.

60. Miler, N.; Kulus, D.; Woźny, A.; Rymarz, D.; Hajzer, M.; Wierzbowski, K.; Nelke, R.; Szeffs, L. Application of wide-spectrum light-emitting diodes in micropropagation of popular ornamental plant species: a study on plant quality and cost reduction. In Vitro Cell Dev. Biol. Plant 2019, 55, 99-108.

61. Solymosi, K.; Schoefs, B. Etioplast and etio-chloroplast formation under natural conditions: the dark side of chlorophyll biosynthesis in angiosperms. Photosynth. Res. 2010, 105, 143-166.

62. Lee, S.-H.; Tewari, R.K.; Hahn, E.-J.; Paek, K.-Y. Photon flux and light quality induce changes in growth, stomatal development, photosynthesis and transpiration of Withania somnifera (L.) Dunal. plantlets. Plant Cell Tiss. Organ Cult. 2007, 90, 141-151.

63. Folta, K.M.; Maruhnich, S.A. Green light: a signal to slow down or stop. J. Expt. Bot. 2007, 58, 3099-3111.

64. Banerjee, R.; Schleicher, E.; Meier, S.; Viana, R.M.; Pokorny, R.; Ahmad, M.; Bittl, R.; Batschauer, A. The signaling state of Arabidopsis scryptochrome 2 contains flavin semiquinone. J. Biol. Chem. 2007, 282, 14916-14922.

65. Wang, Y.; Maruhnich, S.A.; Mageroy, M.H.; Justice, J.R.; Folta, K.M. Phototropin 1 and cryptochrome action in response to green light in combination with other wavelengths. Planta 2013, 237, 225-237.

66. Goggin, D.E.; Steadman, K.J. Blue and green are frequently seen: responses of seeds to short- and mid-wavelength light. Seed Sci. Res. 2012, 22, 27-35.

67. Bian, Z.-H.; Cheng, R.-F.; Yang, Q.-C.; Wang, J.; Lu, C. Continuous light from red, blue, and green light-emitting diodes reduces nitrate content and enhances phytochemical concentrations and antioxidant capacity in lettuce. J. Am. Soc. Hortic. Sci. 2016, 141, 186-195.

68. Semiarti, E.; Purwantoro, A.; Indrianto, A. In vitro culture of orchids: the roles of class-1 Knox gene in shoot development. J. Biol. Res. 2014, 20, 18-27.

69. Find, J.; Grace, L.; Krogstrup, P. Effect of anti-auxins on maturation of embryogenic tissue cultures of Nordmanns fir (Abies nordmanniana). Physiol. Plant. 2002, 116, 231-237.

70. Shimasaki, K.; Uemoto, S. Micropropagation of a terrestrial Cymbidium species using rhizomes developed from seeds and pseudobulbs. Plant Cell Tiss. Organ Cult. 1990, 22, 237-244. 